\title{
Dynamics of injectable contraceptive use in India
}

The Evidence Project

Follow this and additional works at: https://knowledgecommons.popcouncil.org/departments_sbsr-rh

Part of the Demography, Population, and Ecology Commons, Family, Life Course, and Society Commons, International Public Health Commons, and the Women's Health Commons How does access to this work benefit you? Let us know!

\section{Recommended Citation}

The Evidence Project. 2018. "Dynamics of injectable contraceptive use in India: Quality of care received and interim results three months after insertion," research brief. Washington, DC: Population Council, The Evidence Project.

This Brief is brought to you for free and open access by the Population Council. 


\section{Dynamics of Injectable Contraceptive Use in India}

\section{Quality of care received and interim results} three months after first injection

\section{KEY RECOMMENDATIONS}

Disseminate messaging about potential side effects of the injectable, including amenorrhea or other changes to menstruation

The findings demonstrate a need to provide information about side effects to clients. In particular, providers and accredited social health activists (ASHA) should inform women that amenorrhea is a potential side effect and alleviate any concerns related to fertility. Furthermore, social behavioral change programs may consider including specific messaging on injectables and amenorrhea in addition to other common side effects.

\section{Institutionalize quality of care in pre-service trainings for all family planning providers and} frontline health workers

To improve quality of care during family planning visits for all contraceptive methods, providers and frontline health workers should receive training focusing on all four domains of quality of care: 1) respectful care, 2) counseling to enable appropriate method selection, 3) counseling on effective use of method chosen, and 4) information on continuation of contraceptive use and care. Particularly for injectable users, many did not want any more children so there is an opportunity to counsel them on a range of methods that include long-acting and permanent methods.

\section{Engage husbands of recent adopters of contraception}

Most women who discontinued the injectable spoke to their husband about their desire to stop using the method. The advice given by most of these husbands was to stop using the method and only seven percent suggested switching to another modern method. As women are going to their husbands for support, there is an opportunity to improve continuation and switching to a modern method if husbands are equipped with relevant information.

Train frontline health workers to visit recent injectable adopters to answer and address concerns about injectable side effects, and counsel women on method switching

Frontline health workers can play a key role in promoting modern method switching among recent adopters of the injectable who are dissatisfied with the method. ASHAs should visit all women who are using the injectable to a) understand their concerns with the method, b) understand their fertility desires, and c) help them manage any side effects they might experience. They should also encourage those who want to stop the injectable but continue preventing pregnancy to switch to another suitable method. 


\section{INDIA CONTRACEPTIVE USE DYNAMICS LONGITUDINAL STUDY METHODS}

Through the Evidence Project, Population Council researchers are conducting a longitudinal study of 2,699 married women aged 15-49 who began using IUD/PPIUD, injectable, or oral contraceptive pill (OCP). These reversible contraceptive users are first being interviewed within one month of starting the method (known as the enrollment survey) and at 3-, 6- and 12-months follow-up. Respondents from Haryana and Odisha states in India were enrolled into the study from December 2016 to October 2017 (see Map 1). In Haryana, all respondents were recruited through accredited social health activists (ASHAs) at the community level. In Odisha, PPIUD users were recruited at government health facilities, interval IUD and OCP users were recruited primarily through ASHAs, and injectable users were recruited primarily at non-governmental organization (NGO) facilities.

The purpose of this research study is to provide evidence that can be used to strengthen the family planning program and meet the needs of reversible contraceptive users who want to prevent pregnancy in India. With support from USAID/India, Population Council researchers are exploring contraceptive use dynamics of married women by conducting a cohort study with the following research objectives:

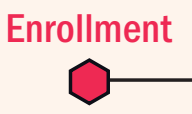

Month 3

Month 6

\section{BACKGROUND}

Injectable contraceptive methods (DMPA and Net-En) have been approved for private sector provision in India since 1993 (FHI, 2010). However, a very small proportion of women use injectables: injectable use among currently married women has remained low over time at less than 0.05 percent in 1992-93, 0.1 percent in 2005-06, and 0.2 percent in 2015-16 (IIPS, 1995; IIPS and Macro International, 2007; IIPS and ICF, 2017). In 2016, injectables were included in India's National Family Planning Program with the introduction of Antara, a brand of DMPA, a three-month progestin-only injectable contraceptive (MOHFW, 2016b). Under Mission Parivar Vikas (Family Development Mission), the Antara program rolled out injectables to the sub-center level in priority districts (identified as having a total fertility rate of at least three children per woman), and at medical colleges and district hospitals in all states (MOHFW, 2016a, MOHFW, 2017a, MOHFW, 2017b). Through the introduction of Antara, the Indian Government is
1. To assess one-year modern spacing contraceptive discontinuation rates by modern spacing methods (postpartum IUD/interval IUD, injectables, OCPs) among a cohort of modern spacing contraceptive users.

2. To measure influencing facilitators for contraceptive continuation and discontinuation, including intensity of experienced side effects.

3. To measure the Method Information Index (MII) that measures client's recall of counseling information received.

4. To assess influMap 1 Itudy Implementation Sites encing factors that lead to contraceptive switching or non-switching.

5. To explore providers' attitudes about contraceptive discontinuation and switching, and their practices with clients who want to discontinue or switch.

Month 12 increasing its basket of method choice in an effort to achieve its FP2020 goals.

Given that roll out of the injectable is ongoing throughout India, it is important to understand the experiences of current injectable users. This brief describes the characteristics of a sample of injectable users in India, reported quality of care they received at the time of first injection (this study did not observe providers during counseling interactions), contact with frontline health workers, and continuation three months after initial injection. Briefs focusing on oral contraceptive pills and IUD/ PPIUD are available as well (see Box 1) but are not the focus of this brief.

\section{METHODS}

Box 1 presents the methodology of the longitudinal study of reversible contraceptive users in India. Of 2,699 users enrolled into the study, 581 were injectable users and are the focus of this brief. 


\section{RESULTS}

\section{BACKGROUND CHARACTERISTICS}

The median age of injectable users enrolled in this study was 28 years, with a range from 18 to 46 years. Nearly half of respondents had attended secondary school or higher (46\%), while 30 percent had never attended school (Figure 1). Two-thirds of respondents were Hindu (67\%) and one-third were Muslim (32\%). Most respondents were homemakers (94\%), two percent were teachers/clerks and two percent were factory/production workers. While all respondents were married, about nine percent were not living with their husband at the time of the enrollment survey. Fifty-four percent owned mobile phones.

\section{Figure 1}

\section{Background characteristics of injectable users $(n=581)$}
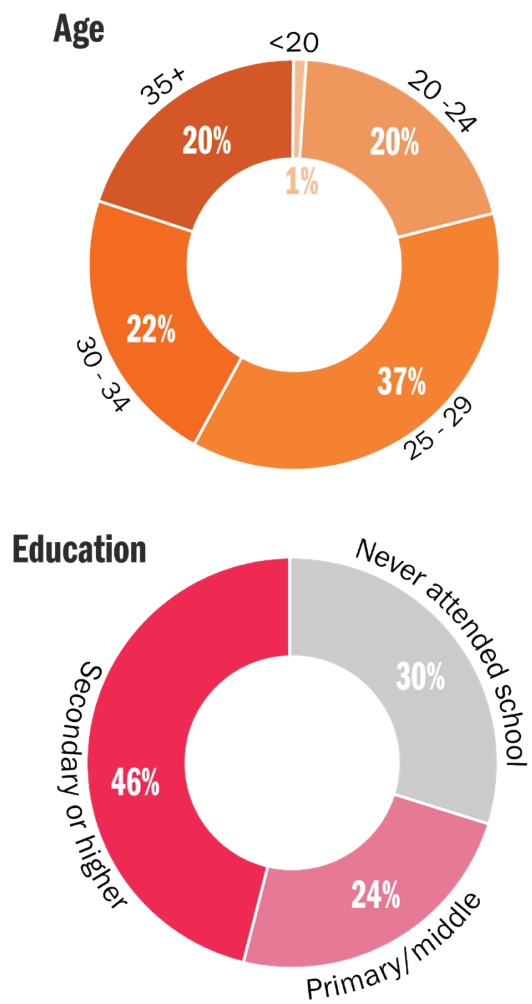

Two-thirds of injectable users in this sample (69\%) had used contraception in the past. Among those who reported previously using a method $(n=424)$, the most recently used methods were the OCP (32\%), condoms (27\%), abstinence (10\%), withdrawal (10\%), injectables (10\%), IUD (5\%), rhythm method (4\%), female condoms (1\%), lactational amenorrhea method (1\%), or the emergency contraceptive pill (1\%). The median age at first contraceptive use was 24 years. (Data not shown).

Nearly all injectable users had at least one living child (over 99\%). One-quarter had one child (25\%), 39 percent had two children, and 36 percent had three or more. More than three-quarters of respondents did not want any children in the future (Figure 2, 78\%). Twelve percent wanted to wait more than two years before having a child, six percent wanted to wait one to two years, one percent wanted a child within the next year, and four percent were undecided.

\section{Figure 2}

\section{Percent distribution of injectable users by fertility preferences at enrollment ( $n=581)$}

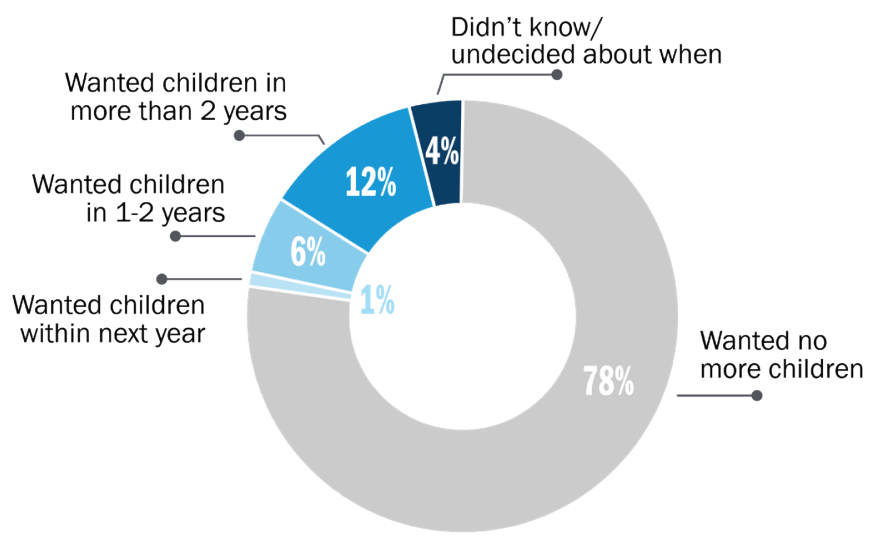

\section{QUALITY OF CARE RECEIVED}

Forty-six percent of respondents received their first administration of the injectable at an NGO clinic. Thirty-seven percent received their first injection from a government health facility, 11 percent from a medical store, 4 percent from a private facility, and 2 percent from a frontline health worker. Figure 3 presents 22 items measuring quality of care received during this visit. These measures of quality are broken down into four domains of process quality (Jain, Townsend \& Ramarao 2018): 1) respectful care, 2) method selection, 3) effective use of the selected method, and 4) continuity of contraceptive use and care (see Box 2).

\section{Respectful care}

Injectable users reported high levels of respectful care at initial visit. Nearly all women reported a) being treated well or very well by the provider (99\%), b) that their questions were answered to their satisfaction (98\%), and c) that they were allowed to ask questions (92\%). Most felt that others couldn't hear $(87 \%)$ or see $(82 \%)$ them during their visit, and that their information would be kept confidential (86\%).

\section{Method selection}

The majority of injectable users reported that their provider asked their preferred family planning method (86\%), their desire for another child (85\%), 
Box 2

\section{What is quality of care?}

Measures of quality are broken down into four domains of process quality (Jain et al., 2018):

1. Respectful care: Concerns interpersonal interactions between the provider and client and assesses aspects of privacy and confidentiality.

2. Method selection: Questions focus on information that a provider should seek to enable appropriate method selection at the decision-making point.

3. Effective use of the selected method: Information given to the respondent about the method selected.

4. Continuity of contraceptive use and care: Includes follow-up appointments and the ability to change methods.

\section{Figure 3}

Aspects of process quality during initial visit reported by injectable users ( $n=581$ )

\section{RESPECTFUL CARE}

$\begin{array}{r}\text { Treated well by provider } \\ \text { Questions answered to satisfaction } \\ \text { Respondent allowed to ask questions } \\ \text { Felt audio privacy } \\ \text { Felt information will be kept confidential } \\ \text { Felt visual privacy } \\ \hline\end{array}$

\section{METHOD SELECTION}

Was asked preferred FP method
Was asked desire for another child
Was asked preferred timing of next child
Was asked previous FP experience
Was told about other methods
Received information about methods that protect against STls
Received information without any method being promoted
HFFECTIVE USE OF METHOD SELECTED
How chosen method works
Side effects of the method
How to manage problems
Warning signs associated with the method

Told about timing of next visit

$$
\begin{aligned}
& \text { Given appointment card for follow-up visit } \\
& \text { Possibility of switching the method } \\
& \text { Told about other sources of supply }
\end{aligned}
$$

and their preferred timing of next child (80\%). Slightly fewer were asked about their previous family planning experience (72\%), and two-thirds were told about other methods (66\%). Only 40 percent received information about methods that protect against STIs and 38 percent received information without any method being strongly encouraged.

\section{Effective use of selected method}

Most respondents were told how to use the method (92\%) while only two-thirds were told how the method works (67\%). Less than half of respondents were told about both the method's side effects as well as what to do if they experienced side effects (45\%). Of the potential side effects of the injectable, the most common mentioned by providers were irregular menstruation (39\%), spotting (17\%), weight gain (14\%), backache (11\%), and nausea (11\%). Just 43 percent were told of the warning signs of the method.
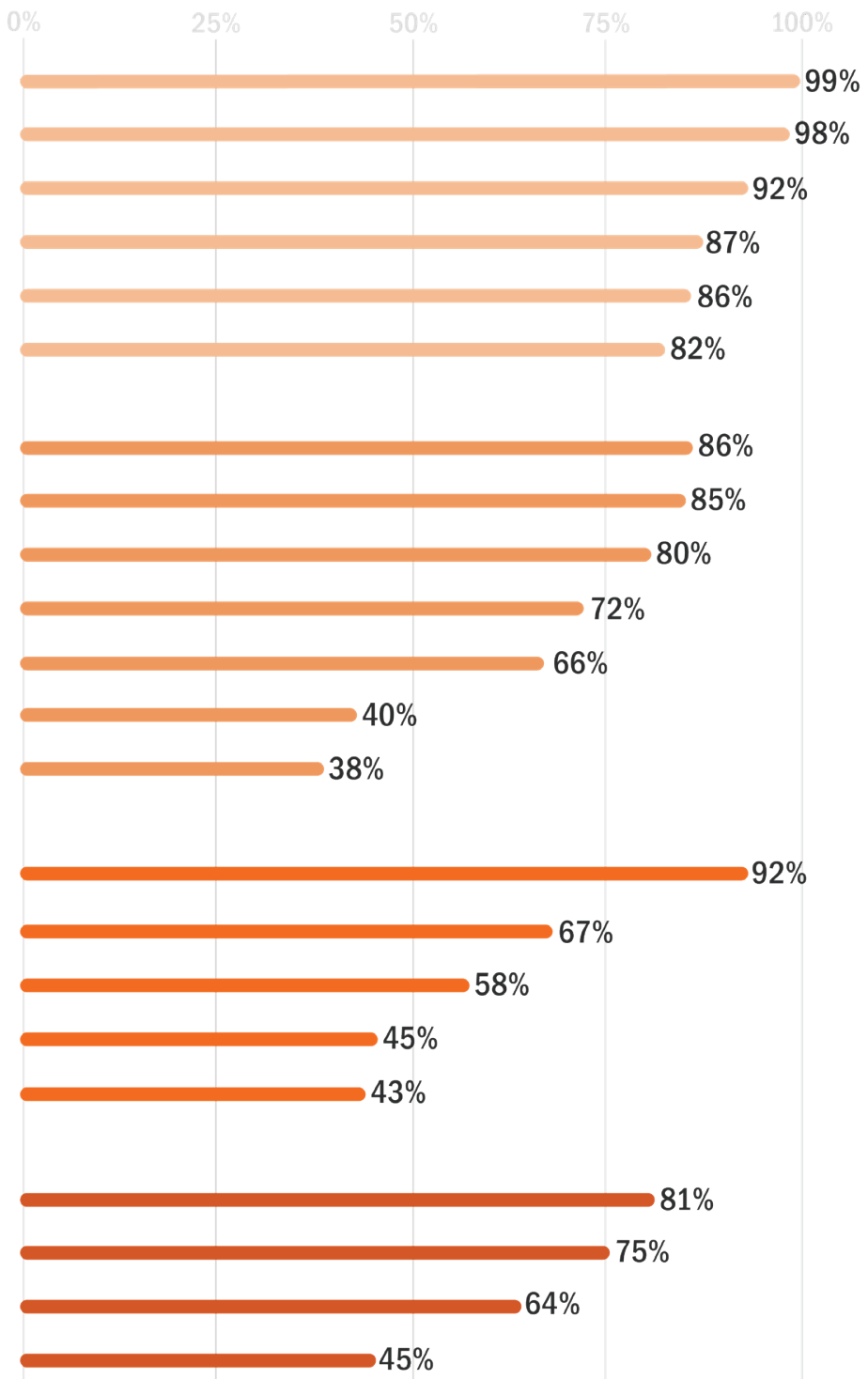


\section{Continuity of contraceptive use and care}

Four in five injectable users (81\%) were told when to return to the facility for their next injection, and three quarters were given an appointment card for this visit (75\%). Sixty-four percent were told about the possibility of switching to other methods if the injectable was not suitable, while only 45 percent were told of other sources of injectable supply.

\section{CONTRACEPTIVE METHOD DECISION MAKING}

All respondents were asked who made the final decision about the method they received at enrollment after discussions with the provider (Figure 4). Among injectable users, 96 percent reported that they were involved in the final decision: 35 percent made the final decision by themselves, 53 percent made the final decision together with their husband, and eight percent made the final decision together with their health provider. Four percent reported that their husband, the provider, or someone else made the final decision. Ninety-eight percent of respondents received the method that they wanted (data not shown). Reasons why women did not get their preferred method was not collected in this study.

\section{CONTACT WITH FRONTLINE HEALTH WORKERS}

At enrollment, injectable users were asked about their contact with frontline health workers. Less than half had ever received information from a frontline health worker (45\%). Regarding information about the injectable, 43 percent had received information about the injectable from an ASHA, one percent had received this information from an auxiliary nurse

Figure 4

Percent distribution of injectable users by who made the final decision about contraceptive method $(n=581)$

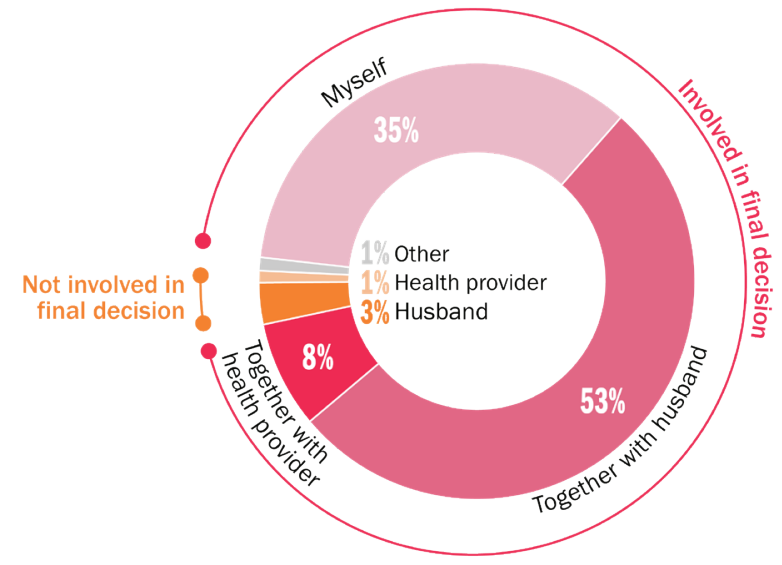

midwife (ANM), and 0.3 percent had received this information from an Anganwadi worker (AWW). In the three months preceding the survey, 55 percent did not meet with a frontline health worker, 9 percent met with a frontline health worker once, 28 percent met two to five times, and 8 percent met more than five times. (Data not shown).

Figure 5 presents the topics discussed with frontline health workers in the three months preceding the survey. The most commonly discussed topic was available contraceptive methods (22\%), followed by long acting methods (15\%), fertility intentions (14\%), side-effects of methods (10\%), how to deal with side effects ( $7 \%)$, and return to fertility (3\%).

\section{CONTRACEPTIVE USE AT THREE MONTHS FOLLOWING INITIAL INJECTION}

Seventy-eight percent of injectable users completed the three-month follow-up survey $(n=455)$. Three months after their first injection, 76 percent were still using the injectable method. The 24 percent that discontinued the injectable includes 8 percent who switched to another modern method, 4 percent who switched to a traditional method, and 11 percent who stopped contraceptive use altogether. The modern methods switched to after the injectable were the OCP ( $5 \%$ of all injectable users interviewed at three-month), condom (2\%), IUD (1\%), and male and female sterilization ( $0.2 \%$ each). Among those who discontinued the injectable and did not switch to another method ( $n=51)$, most still had a need for family planning as 69 percent did not want any children in the future and 10 percent wanted to wait more than two years before having a child.

Figure 5

Topics discussed with frontline health workers in the three months preceding the survey reported by injectable users $(n=581)$

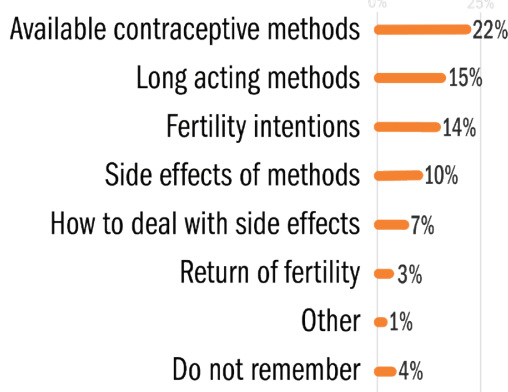

Multiple responses were possible 


\section{Reasons for injectable discontinuation}

Respondents who discontinued the injectable (both those who discontinued contraception altogether and those who switched to another method, $n=104$ ) provided one or more reasons why they discontinued the method (Figure 6). Common reasons named were having not menstruated since starting the method (57\%), and side effects and health concerns (33\%). Other reasons mentioned were husband's opposition (16\%), injectable use interfered with the body's normal processes (9\%), husband not living at home (8\%), lack of access to the method/too far (7\%), mother-in-law's opposition (5\%), not having sex (5\%), and method failure/pregnancy (4\%). Only 3 percent discontinued the injectable because they wanted to become pregnant.

\section{Figure 6}

\section{Reasons for discontinuation reported by injectable discontinuers at three month follow-up ( $n=104)$}

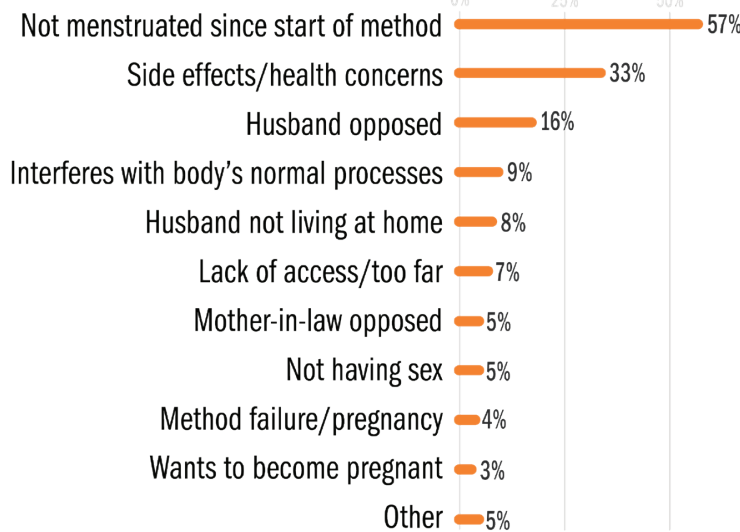

Multiple responses were possible

\section{Discussions about discontinuation}

Among respondents who had stopped using the injectable by three months (including those who switched and those who discontinued contraception altogether, $n=104)$, fifty-two percent spoke to their husband about their desire to stop using the method (Figure 7). Twenty-seven percent spoke to an ASHA, 13 percent to a provider, seven percent to their mother-in-law, two percent to a neighbor, and one percent to a sister-in-law. Thirty-five percent of women spoke to no one about their desire to stop using the injectable. Respondents were also asked if they spoke to the same provider who gave them the injectable about stopping the method: 38 percent spoke to the same provider and 41 percent returned to the same facility (data not shown).
Figure 7

Individuals with whom injectable discontinuers discussed their desire to discontinue the method ( $n=104)$

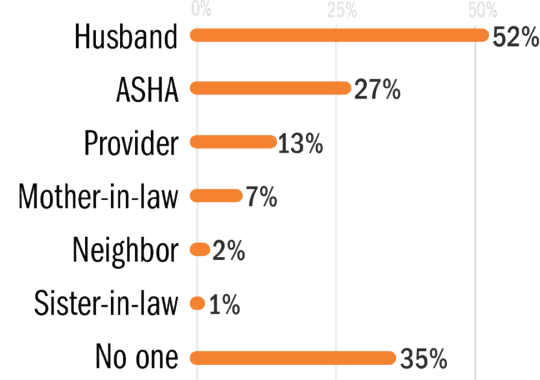

Multiple responses were possible

Among respondents who spoke to an ASHA about their desire to stop the method $(n=28), 13$ women reported that the ASHA asked them to stop using the method, seven reported that the ASHA gave them medicine for side effects, and four said the ASHA accompanied them to a health center. Three said the ASHA counseled them about other methods and one said the ASHA told her to switch to a different method (data not shown). Among those who spoke to their husband $(n=54), 42$ reported that their husband asked them to stop using the injectable. Six respondents said their husband told them to see a doctor/ ASHA, four said their husband asked them to switch to another method, one said her husband asked her to continue the injectable and one said her husband suggested getting medication (data not shown).

Figure 8 presents the proportion of injectable discontinuers who switched to another modern method by whom they spoke to about their desire to discontinue. Those who spoke to an ASHA only were most likely to switch to another modern method (57\%). Among those who spoke to both an ASHA and their husband, 36 percent switched to another modern method, while those who spoke to their husband only and those who spoke to neither their husband nor an ASHA were least likely to switch to another modern method (28 and 25 percent, respectively).

Figure 8

Percent of injectable discontinuers who switched to a modern method, by whom they spoke to

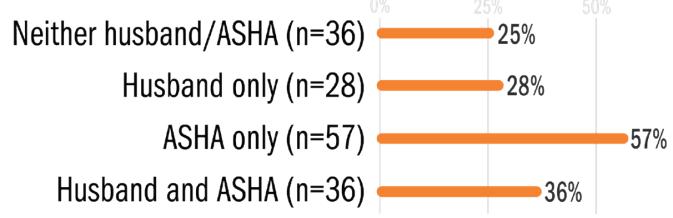




\section{DISCUSSION}

Understanding the experiences of the small but growing population of women choosing the injectable is important as the Government of India continues to rollout injectable contraceptive methods in the public sector. In this study, most injectable users were age 20-29 years, educated, and did not want any more children. Most were involved in the final decision about which contraceptive method to use after discussions with their provider. Less than half had spoken with a frontline health worker at least once in the three months preceding the survey.

Injectable users' reports demonstrate mixed results of their interactions with providers at initial visit. Some reported aspects of quality were high, such as items under the respectful care domain. There is an opportunity for improvement in other domains, such as providing important method-related information and alternative method choices in case the injectable is not suitable. Many women discontinued the injectable method because they had not menstruated since starting the method. Providers should include information on amenorrhea in routine injectable counseling so potential users know to expect this as a potential result of use.
Injectable users' responses about their initial visit may have recall bias, but this is likely to be minimal as they were interviewed within one month of the visit in which they initiated the method. Additionally, 45 percent of injectable users had received information from a frontline worker about contraceptive methods in the three months preceding the enrollment survey, but responses about quality of care at initiation of injectable use may not have included this prior counseling.

Speaking to an ASHA only about the desire to discontinue the injectable appears to have a positive effect on women's switching behavior as fiftyseven percent of respondents who spoke to an ASHA only switched to another modern method. When women spoke to their husbands in addition to an ASHA, on the other hand, the positive effect of the ASHA on method switching was attenuated and the proportion switching to a modern method went down to thirty-six percent. It is therefore critical to both ensure ASHAs are visiting new users of injectables and to equip husbands with information to encourage their wives to switch to another modern method of family planning in cases where the desire to prevent pregnancy remains.

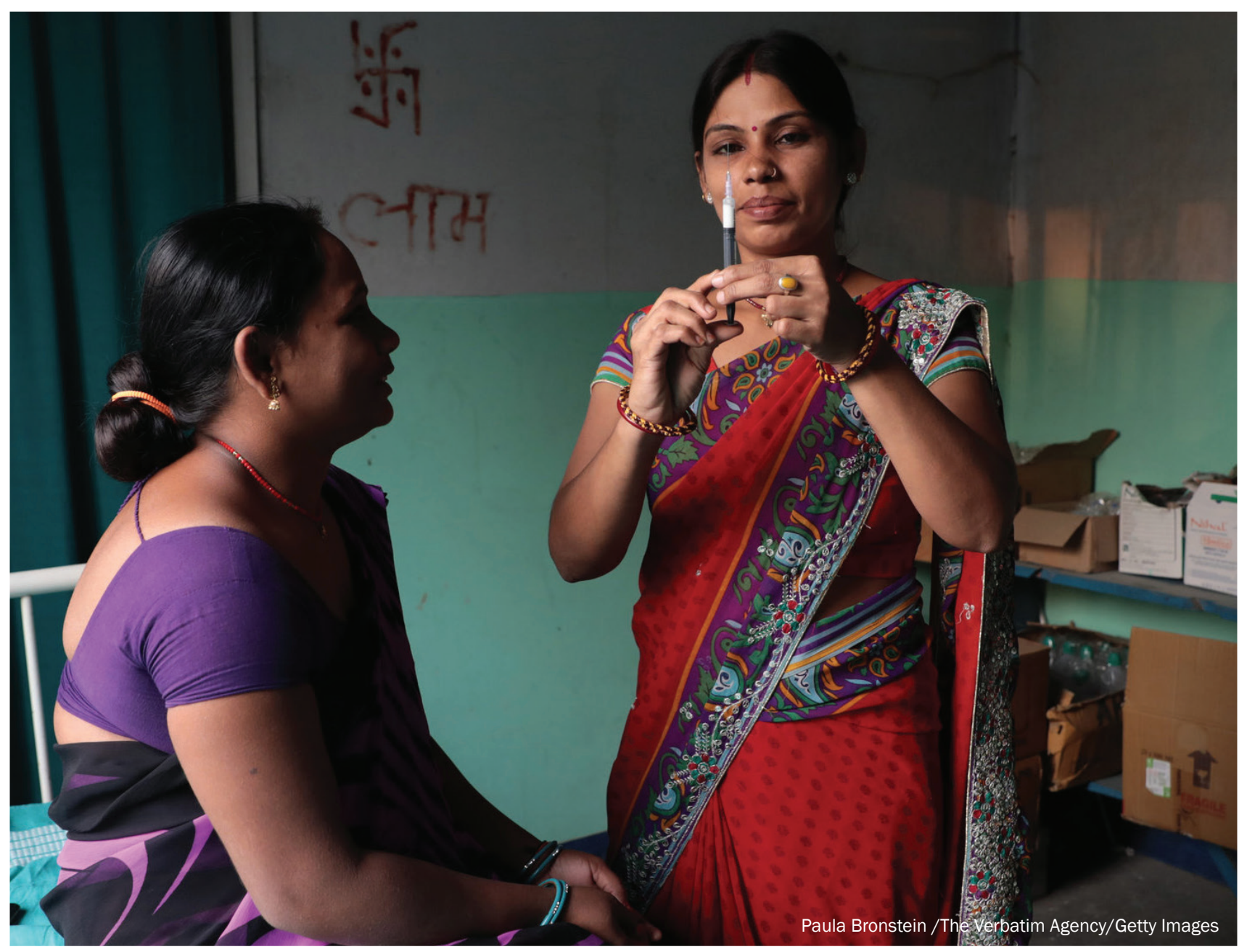




\section{REFERENCES}

Family Health International (FHI). 2010. India Brief 3: Types, Availability, and Use of Injectables. New Delhi: FHI.

Family Planning 2020 (FP2020). 2018. India Commitment Self-Reporting Questionnaire 2018. FP2020, Washington, DC.

FHI 360. 2013. India e-FP Synthesis Brief \#2: Injectable contraception in India: What does the future hold? New Delhi: FHI 360.

International Institute for Population Sciences (IIPS). 1995. National Family Health Survey (MCH and Family Planning), India 1992-93. Bombay: IIPS.

International Institute for Population Sciences (IIPS) and ICF. 2017. National Family Health Survey (NFHS-4), 2015-16: India. Mumbai: IIPS.

International Institute for Population Sciences (IIPS) and Macro International. 2007. National Family Health Survey (NFHS-3), 2005-06: India: Volume I. Mumbai: IIPS.

Jain A, Townsend J \& Ramarao S. 2018. Proposed metrics to measure quality: Overview. Population Council, NY.
Ministry of Health and Family Welfare. 2016a. Mission Parivar Vikas. National Health Mission, Ministry of Health and Family Welfare, Government of India, New Delhi.

Ministry of Health and Family Welfare. 2016b. Reference Manual for Injectable Contraceptive (DMPA). National Health Mission, Ministry of Health and Family Welfare, Government of India, New Delhi.

Ministry of Health and Family Welfare. 2017a. Health Ministry launches two new contraceptives. Press Information Bureau, Ministry of Health and Family Welfare, Government of India, New Delhi.

Ministry of Health and Family Welfare. 2017b. Rollout of Injectables. National Health Mission, Ministry of Health and Family Welfare, Government of India, New Delhi.

World Health Organization. 2015. WHO Statement on Depot-medroxyprogesterone acetate (DMPA). World Health Organization, Geneva.

\section{THE EVIDENCE PROJECT}

Population Counci

4301 Connecticut Ave. NW

Washington, DC 20008

tel: +202 2379400

evidenceproject@popcouncil.org (e) USAID

The Evidence Project is made possible by the generous support of the American people through the United States Agency for International Development (USAID) under the terms of cooperative agreement no. AIDOAA-A-13-00087. The contents of this document are the sole responsibility of the Evidence Project and Population Council and do not necessarily reflect the views of USAID or the United States Government.

Evidence

The Evidence Project uses implementation science-the strategic generation, translation, and use of evidence-to strengthen and scale up family planning and reproductive health programs to reduce unintended pregnancies worldwide. The Evidence Project is led by the Population Council in partnership with the Population Reference Bureau.

Suggested Citation: The Evidence Project. 2018. "Dynamics of injectable contraceptive use in India: Quality of care received and interim results three months after insertion," Research Brief. Washington, DC: Population Council, The Evidence Project.

(C) 2018 The Population Council, Inc. 